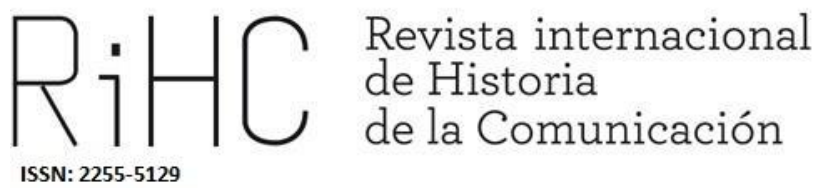

\title{
REPRESENTACIONES DE LO \\ ALTERNATIVO EN EL MADRID \\ DEL TRÁNSITO A LA \\ DEMOCRACIA: EL CASO DE LA \\ (CONTRA)CULTURA \\ MEDIÁTICA DE LAS RADIOS \\ LIBRES (1976-1989)
}

Representations of the alternative in Madrid during the transition to democracy: the case of free radios' mediatic (counter)culture (1976-1989)

DOI: https://dx.doi.org/10.12795/RiHC.2020.i15.05

Recibido: 18-9-2020

Aceptado: 8-10-2020

Publicado: $30-12-2020$

José Emilio Pérez Martínez

Sorbonne Université, Francia

joseemiliopm@gmail.com

ORCID (iD) 0000-0003-1880-5424 
Resumen: En la década de 1980, proliferaron en el éter español multitud de pequeñas emisoras radiofónicas que plantearon una nueva forma de hacer y entender la comunicación, y que constituyeron un nuevo movimiento social: el de las radios libres. Un movimiento que nació y creció dentro de una subcultura alternativa, cercana a la izquierda radical, para la que jugó el papel de instancia de producción y reproducción ideológica. En estas páginas veremos cómo la contracultura mediática que rodeó a estas emisoras, generó un estilo subcultural basado en la transformación y resignificación del lenguaje que ayudó a construir una identidad y una representación de lo alternativo en el Madrid de la Transición.

Palabras clave: radios libres, comunicación alternativa, subcultura, Transición española

\begin{abstract}
:
In the 1980s, a multitude of small radio stations proliferated in the Spanish ether, posing a new way of doing and understanding communication, and constituting a new social movement: that of free radios. A movement that was born and grew within an alternative subculture, close to the radical left, for which it played the role of an instance of ideological production and reproduction. In these pages we will see how the media counterculture that surrounded these stations generated a subcultural style based on the transformation and resignification of language that helped to build an identity and a representation of the alternative in Madrid during the Transition to democracy.
\end{abstract}

Keywords: free radios, alternative communication, subculture, Spanish Transition

\title{
Introducción y metodología
}

A finales de la década de 1970, en pleno proceso de tránsito a la democracia, surgieron en el éter español las primeras radios libres. Estas emisoras de frecuencia modulada y baja potencia intentaron, con su praxis cotidiana, dar voz a todos aquellos colectivos que no disponían de ella en los medios de comunicación generalistas. A este primer objetivo, se sumó pronto la búsqueda de un nuevo horizonte de cambio social, que mostraba su descontento con la articulación de las nuevas libertades democráticas en España.

A pesar de su longevidad - siguen existiendo proyectos de este tipo hoy en día- y de su impacto en la década de 1980, el movimiento de las radios libres es uno de los grandes desconocidos para la historiografía y los estudios de comunicación españoles. La poca atención académica que recibe la radio, en favor de medios más visuales y en los que el acceso a documentación es más sencillo (Rodero, 2009; Lacey, 2009 y 2018), se acentúa hasta, prácticamente, el vacío, al tratar de, en palabras de Emili Prado, estas "otras radios" (Prado 1999). Fue Prado, precisamente, uno de los pioneros en el estudio de este tipo de emisoras, tanto desde una perspectiva internacional -Italia, más concretamente (1983)-, como estatal (1981). A estos textos podemos sumar otros acercamientos tempranos como los de Miguel Aguilera (1985) o Francesc Deó y otros 
(1985). Todos ellos conformaron la primera generación de estudios sobre las radios libres en España. En la década de 1990 podemos encontrar estudios que versaron, total o parcialmente, sobre este tipo de emisoras, como los de María Teresa Santos Díez sobre la radio vasca (1994), o los de Martín (1998), relacionando las radios libres con otros movimientos sociales. A partir de los 2000 , debemos resaltar la labor realizada por toda una serie de investigadores e investigadoras que, en gran medida, han terminado integrándose en la Red de Investigación en Comunicación Comunitaria, Alternativa y Participativa (RICCAP), un importante polo de reflexión sobre el Tercer Sector de la comunicación. Si bien es cierto que la gran mayoría de su producción se realiza desde los estudios de comunicación y se centra, principalmente, en las radios comunitarias fenómeno ligeramente distinto a las emisoras libres y algo posterior en el tiempo-, sus contribuciones son de indudable valor, pues versan sobre un amplio rango temático que va desde la situación legal de estos medios (García García, 2013) a la participación de los jóvenes en ellos (Lema, Rodríguez Gómez y Barranquero, 2016), pasando por su papel como elementos de integración social (García García, 2017) o de dinamizadores de la movilización ciudadana (Barranquero y Meda, 2015).

Desde el punto de vista de la recuperación del pasado de estas radios, es destacable la publicación reciente de trabajos que tratan el fenómeno en Cataluña (Camps Durban, 2019) - atendiendo a la totalidad del espacio catalán de comunicación-, el País Vasco (Pascual, 2019) - relacionando estos proyectos con otras formas contraculturales como los fanzines o las okupaciones - y en la Comunidad Autónoma de Madrid durante la década de 1980 (Pérez Martínez, 2018).

Partiendo de todos estos trabajos previos, el objetivo del presente artículo es analizar, por un lado, cómo este tipo de emisoras madrileñas - que nacieron en el seno de lo que hemos venido a considerar una subcultura alternativa, compuesta por distintos sectores de la izquierda radical- se convirtieron en instancias de producción ideológica (Althusser, 2014). Por otro lado, examinaremos su papel en la transmisión de mapas de significados y representaciones que, a través de mecanismos como el bricolage (Clarke, 2014) y de la puesta en circulación de discursos - tanto a través de las ondas como de otros medios-, fueron asumidos por los jóvenes que integraban dicha subcultura, llegando a crear un espacio contrahegemónico (Williams, 2009: 155).

Estudiaremos, mediante el análisis de casos concretos, cómo estas radios ayudaron a crear, a través de esta contracultura mediática, una identidad propia para los miembros de esta subcultura, y su representación de la sociedad española de aquellos años, marcando una clara diferencia entre el "ellos" y el "nosotros", a la par que daban cobertura y apoyo a las distintas movilizaciones sociales que se estaban dando en las calles madrileñas.

Este texto se enmarca en un esfuerzo investigador más amplio, que se viene desarrollando durante más de una década. A lo largo de estos años, y como parte 
constituyente y clave de esta recuperación sistemática del pasado de las radios libres, se ha intentado suplir la marcada ausencia de documentación en archivos al uso con la construcción de un corpus documental que sirviese de punto de partida para cualquier investigación relacionada con el tema. Debemos apuntar, sobre este conjunto, que está constituido por una colección particular que reúne: materiales hemerográficos publicaciones con contenidos sobre radios libres, tanto generalistas como alternativas; más de un centenar de horas de grabaciones en audio -procedentes de internet, digitalización de casetes, colecciones privadas, etc.-; más de una treintena de entrevistas semiestructuradas de final abierto a miembros de distintas emisoras; $y$ materiales de diversa naturaleza producidos por las distintas instancias del movimiento -emisoras, coordinadoras, etc.-, que van desde guiones originales de programas a pegatinas, pasando por pasquines, posters o bonos de ayuda.

Las reflexiones contenidas en estas páginas se han realizado después de analizar detalladamente cada uno de los elementos integrantes de este amplio y único corpus documental, ponerlos en relación y someterlos a preguntas de investigación. En definitiva, y de acuerdo con Enrique Moradiellos, se ha seguido el método de trabajo del historiador: aquel que, lejos de ser "una mera descripción de los hechos del pasado", consiste "en la construcción de un pasado histórico en forma de relato narrativo" que parte de "las fuentes documentales primarias legadas" y que se lleva a cabo mediante un método inferencial e interpretativo", en el que "es imposible eliminar al propio sujeto gnoseológico" y que "no puede ser arbitrario sino que debe estar apoyado y contrastado por las pruebas que existan al respecto" (1994: 9). Una metodología que arroja, como podremos comprobar en estas páginas, excelentes resultados.

Así pues, aunque la reconstrucción narrativa que aquí presentamos se ha apoyado en el trabajo con la colección antes mencionada, en estas páginas, y para adaptarnos a la extensión y requisitos formales de los artículos científicos, hemos querido ejemplificarla con estudios de caso concretos, lo que nos ha llevado a seleccionar una pequeña muestra de documentos. Por lo tanto, ilustrarán nuestras ideas las siguientes fuentes: una entrevista personal a un miembro fundador de La Cadena del Water, una cuña de la misma emisora, un poema de Radio Cigüeña y un artículo de prensa publicad por uno de los fundadores de Onda Sur.

\section{1 ¿Qué son las radios libres? Notas sobre su definición y su desarrollo}

Cuando hablamos de radios libres hacemos referencia a un fenómeno heterogéneo que, a nivel europeo, surgió en la segunda mitad de la década de 1970 y tuvo su apogeo en 
el decenio siguiente. Con dos claros epicentros, Francia (Lefevbre, 2008) e Italia (Perrotta, 2013), el fenómeno se fue expandiendo progresivamente, con la aparición de emisoras de este tipo en Portugal (Guerra, 2019), Grecia (Thedosiadou, 2010), Holanda (Van der Hoeven, 2014) y, por supuesto, España. Aunque con matices por las distintas realidades nacionales, es posible fijar el origen de este tipo de proyectos en una situación de "anomia comunicacional" (Pérez Martínez, 2017) que se produce en las, más o menos asentadas, democracias occidentales. En estos países, las culturas dominantes propugnan como objetivos socialmente deseables el derecho a la información y la libertad de expresión. A pesar de ello, restringen los canales normalizados para satisfacerlos. La gestión de la comunicación mediante medios públicos u oligopolios privados, hace que se niegue, normalmente, el derecho de acceso de la ciudadanía a los media. Ante esta tensión entre la importancia de dichos objetivos y la imposibilidad de la mayoría social para satisfacerlos, algunos sectores decidieron poner en marcha sus propias emisoras radiofónicas, defendían, así, una nueva forma de entender la comunicación que escapaba al modelo clásico: vertical y excluyente. El abaratamiento de los equipos necesarios para poner en marcha una emisora y el aumento del número de estudiantes de telecomunicaciones y otras áreas afines, fueron otros dos factores que facilitaron la proliferación de estos proyectos.

A pesar de que, como hemos señalado, estamos tratando con un fenómeno diverso, es posible establecer una serie de rasgos comunes que nos permitan definir qué es una radio libre. En primer lugar, suelen pertenecer a asociaciones o colectivos sociales, por lo que, son emisoras cuya propiedad es privada, pero ciudadana. Dado su carácter asociativo, son proyectos que nacen como espacios abiertos y horizontales, en los que cualquier persona podía participar y donde los procesos de toma de decisiones se hacían, principalmente, en asambleas. En su afán por construir un nuevo modelo comunicativo, en el que se superasen las barreras clásicas entre emisor y receptor, estas radios defendieron su autonomía de poderes políticos y económicos. Se caracterizan, por tanto, por no tener ánimo de lucro, lo que las llevó, por ejemplo, a rechazar la emisión de publicidad. Asimismo, emitían al margen de la ley, de forma "alegal", como ellas mismas reconocían.

En este artículo, nos vamos a centrar en la primera fase de su recorrido histórico: desde la aparición de las primeras emisoras hasta el concurso de licencias de 1989, derivado del Plan Técnico Nacional, producto de la Ley de Ordenación de las Telecomunicaciones (LOT) de 1987, primer punto de inflexión para el movimiento. Esta ley fue la primera amenaza grave para su supervivencia a nivel estatal, porque quedar sin licencia tras el concurso suponía enfrentarse a las duras sanciones que recogía la LOT.

En el año 1976 apareció en el éter madrileño Radio La Voz del Pobre, antecedente de lo que fue, más tarde, la primera oleada de emisoras dentro del movimiento de las radios libres. En 1979, comenzó a emitir en Barcelona Ona Lliure, proyecto que se considera, 
tradicionalmente, punto de partida de la radiodifusión libre en España. Durante los primeros compases de los años ochenta, este tipo de emisoras se concentraron alrededor de Cataluña, el País Vasco, Aragón y la Comunidad Valenciana. Para el caso de Madrid, el afianzamiento de la radiodifusión alternativa llegó en los años 1982 y 1983, con la aparición de experiencias como Radio Acción en el Barrio del Pilar, Onda Sur en Villaverde, Radio Luna en el centro, Radio Fhortaleza en Hortaleza y Onda Verde Vallekana en Vallecas.

En mayo de 1983 se celebró en Madrid el VI Encuentro de la Coordinadora Estatal de Radios Libres, primero que tuvo lugar en la ciudad, fuera de la franja norte del país. Como resultado de este VI Encuentro se publicó el Manifiesto de Villaverde, documento clave para el desarrollo de estas emisoras. Tras este hito, su implantación en los barrios de Madrid y en muchas de las localidades de alrededor fue creciendo de forma exponencial. Getafe (Radio Rara), Parla (Radio Tú), Leganés (Radio Piel Roja), Rivas Vaciamadrid (Radio Cigüeña), Morata de Tajuña (Radio Morata), Canillejas (Radio Carcoma), Aluche (Onda Latina), Orcasitas (Radio ELO) o Las Águilas (Radio Las Águilas) fueron algunos de los municipios y barrios en los que aparecieron radios libres.

Por su proximidad geográfica con los poderes políticos y económicos del Estado, las emisoras madrileñas terminaron por constituir un importante nodo de actividad dentro del movimiento. Este protagonismo se intensificó con la labor de Onda Verde y su coordinador, Esteban Ibarra, en la incorporación de las radios españolas a organismos internacionales, como la Federación Europea de Radios Libres (FERL) o la Asociación Mundial de Radios Comunitarias (AMARC).

También resulta necesario destacar el apoyo que dieron estas radios a las distintas luchas que se dieron en las calles madrileñas durante estos años -anti-OTAN, ecologista, vecinal, etcétera-. Esta implicación dio lugar a situaciones tan polémicas como el arresto de uno de los locutores de Radio La Voz de la Experiencia de la Cadena del Water -o simplemente la Cadena del Water- por supuestamente alentar la violencia en las manifestaciones estudiantiles del año 1987. En parte motivado por esta oposición frontal a sus políticas y en parte por la presión de agentes privados que querían participar, o que venían participando de forma ilegal, en el negocio de la radiodifusión, el gobierno del PSOE aprobó en diciembre de 1987 la ya mentada LOT, que establecía una serie de importantes sanciones que perseguían y castigaban la actividad de las radios libres, como el uso de aparatos autoconstruidos y no homologados.

En consecuencia, desde la aprobación de la LOT, el movimiento al completo, incluyendo las emisoras madrileñas, centró su actividad en evitar los cierres, esquivar las sanciones y en preparar el concurso de licencias que había de celebrarse. Una eventual legalización abría una ventana de posibilidades para este tipo de radios, por lo que se dedicaron muchos esfuerzos a establecer contactos con la Dirección General de 
Telecomunicaciones, a debatir cuáles eran las mejores condiciones para presentarse a dicho concurso y, finalmente, a presentar los proyectos técnicos para intentar conseguir la concesión administrativa.

Como colofón a una serie de debates y enfrentamientos que venían produciéndose dentro de las radios madrileñas desde 1984, varias fueron las vías para presentarse al concurso de frecuencias. Hubo emisoras, como Onda Verde y la Cadena del Water, que concurrieron en solitario, y hubo otras que lo hicieron conjuntamente, dando lugar a dos plataformas unitarias: la Federación de Radios Libres de la Comunidad de Madrid (FERALICOMA) y la Agrupación de Asociaciones Culturales de Comunicación de la Comunidad de Madrid (AACC-CAM).

Las autoridades impusieron, como requisito para poder optar a una licencia, que cesasen las emisiones de aquellas radios que se encontrasen en situación irregular. En consecuencia, el 12 de marzo de 1989 las voces de nuestras protagonistas desaparecieron del dial. En octubre se procedió a repartir las licencias y, a nivel estatal, dos fueron a parar para el movimiento por la libertad de emisión: una en Valencia, a Radio Klara - aún hoy en activo-, y otra en Madrid, más en concreto en Chinchón pequeña localidad relativamente cercana a la capital-, para FERALICOMA. Ante estos resultados muchas emisoras libres cerraron sus puertas para siempre, como la Cadena del Water; otras tantas, tras un tiempo prudencial, retomaron su actividad y volvieron a dar voz a los "sin voz". La explotación de esta frecuencia por FERALICOMA se tornó especialmente compleja y problemática, lo que hizo que se terminara vendiendo al polémico empresario Ruíz Mateos, pero esto es, sin duda alguna, otra historia.

Habiéndonos acercado brevemente a qué es una radio libre y a cuál fue la evolución del movimiento durante los años que aquí nos ocupan, ha llegado el momento de ver en qué consistía aquella subcultura alternativa en la que surgieron estas emisoras, como paso necesario para entender la cultura mediática que produjeron y el papel que jugó en el Madrid de aquel momento.

\section{La subcultura alternativa y las radios libres}

Tal y como señalamos en la introducción de este artículo, las radios libres nacieron en el seno de un grupo social concreto y determinado, que hemos venido a denominar subcultura alternativa. Dentro de ella, estas emisoras desempeñaron un doble papel. Por un lado, ejercieron de instancias de producción y reproducción ideológica, poniendo en circulación los mapas de significados, la cosmovisión y las representaciones de dicho 
subconjunto social. Por otro, su puesta en marcha y escucha, fueron prácticas culturales que definieron a la propia subcultura. Intentaremos, a continuación, explicar esta realidad y qué implicaciones tiene para la comprensión del fenómeno que aquí estudiamos.

En primer lugar, debemos clarificar que cuando hacemos referencia al término subcultura, lo hacemos partiendo de los planteamientos originales del Centre for Contemporary Cultural Studies de Birmingham (Hall y Jefferson, 2014 y Hebdige, 2004), donde se define como un subconjunto social, pequeño y diferenciado, dentro de una red cultural de clase más amplia - su cultura parental- que intenta solucionar las tensiones que tiene tanto con esta como con la cultura dominante de forma simbólica, normalmente "definiendo su espacio y su yo, mediante la creación de un estilo o sistema simbólico propio" (Martín Cabello, 2006 : 106).

Atendiendo a la clase de la cultura parental, el CCCS diferenció entre subculturas de la clase obrera y de la clase media. Mientras que las primeras se estructuraban colectivamente, distinguían entre el tiempo libre y el de las "instituciones paternas" (escuela, por ejemplo), valoraban el entorno existente (barrio) y solían ser etiquetadas por la cultura dominante como "vandálicas"; las segundas eran más individualistas, generaban contraculturas (Hall, 1970), buscaban instituciones alternativas a las paternas, creaban "enclaves" en los intersticios de la cultura dominante y tenían una forma más política (Martín Cabello, 2006: 113).

Nos encontramos, al hablar de la subcultura alternativa, ante un fenómeno híbrido en cuanto a composición de clase, que reunía características de ambos tipos de subculturas y que era heredera, de alguna forma, de la lucha antifranquista y de la contracultura americana, así como de la crítica sesentayochista. Un espacio en el que confluyeron distintas culturas políticas y activismos, así como individualidades. Era posible por lo tanto encontrar dentro de este espacio a militantes de partidos de la izquierda radical - como el Movimiento Comunista (MC) o la Liga Comunista Revolucionaria (LCR) libertarios - tanto de CNT, como de CGT-, activistas de los movimientos sociales ecologistas, feministas, pacifistas, movimiento vecinal, etc. -, antiguos militantes de partidos políticos que terminaron en el tejido ciudadano o, según avancen los años ochenta, los "autónomos", así como individualidades con inquietudes culturales en un sentido amplio (música, teatro, literatura, etc.), pero fuera del circuito comercial.

Un magma heterogéneo que, sin embargo, compartía, con matices, una visión crítica y alternativa de la sociedad tanto en lo político, como en lo económico, así como en lo cultural. Además de este sentir altermundista, los miembros de este subconjunto social compartieron espacios de sociabilidad y prácticas culturales, como pudieron ser los locales del tejido asociativo de sus barrios, los bares, las manifestaciones, los conciertos, las primeras okupaciones y, cómo no, las propias radios libres. 
Esta opción por lo alternativo tuvo su reflejo en este tipo de radios. Ponerlas en marcha fue una opción política que ahondó en su componente contracultural y escucharlas constituyó una práctica que definía a este subconjunto social, pues en sus emisiones se desplegaron contenidos que reforzaron esa cosmovisión alternativa del mundo: programas dedicados a las movilizaciones sociales, a la realidad de sus barrios, a minorías sociales, a escenas musicales no mayoritarias, etc.

De hecho, estas emisoras jugaron el rol de instancias de producción y reproducción ideológica dentro y fuera de los límites de esta subcultura, ayudando a que sus discursos altermundistas terminasen constituyéndose en contrahegemonía y obligando, en muchos casos, a la cultura dominante del momento - recordemos que el país se encuentra asentando su democracia durante la década de 1980- a terminar incorporando parte de estos a su repertorio ideológico de cara a no perder su posición. Las radios libres, gracias a su horizontalidad y su altermundismo, permitieron que multitud de movimientos sociales se acercasen a sus locales e inundasen sus parrillas, convirtiéndolas en altavoz de sus posiciones. Al ser común, dentro de los ambientes "alternativos" escuchar estas emisoras, dichos discursos circularon en el interior de la subcultura, permitiendo el debate y la reflexión sobre los mismos, bien en los espacios de sociabilidad, bien en antena a través del teléfono.

Este proceso de producción, proyección y reproducción ideológica permitió expandir la cosmovisión altermundista de la subcultura alternativa por distintas capas de la sociedad española, hasta forzar a las clases dominantes a aceptar parcialmente cuestiones como el ecologismo o el feminismo, de cara a mantener su prevalencia en esa negociación constante que es el mantenimiento de la hegemonía social. En la aceptación de reivindicaciones de los movimientos sociales durante estos años influyó, sin duda, el impacto que llegaron a tener estas emisoras durante la década de los ochenta. Un ejemplo claro de esto fue la campaña del referéndum sobre la permanencia de España en la OTAN: las emisoras libres, al igual que todo el espectro de lo alternativo, se volcaron por el "no", de forma que se convirtieron en uno de los principales elementos de difusión de su argumentario.

\section{Representaciones de lo(s) alternativo(s)}

Dentro de los discursos puestos en las ondas por las radios libres, queremos centrarnos, tal y como indicamos en la introducción de este texto, en aquellos que representaban la idea de qué era y quiénes constituían dicha subcultura alternativa. Es decir, nos centraremos en analizar los mecanismos por los que generaron rasgos identitarios diferenciadores e intentaremos comprender sus significados a través del estudio de ejemplos concretos. 
Siguiendo a la Escuela de Birmingham, uno de los elementos diferenciadores fundamentales de las subculturas es el estilo. Para John Clarke, pionero en este tema, en el momento de la creación estilística es "donde la actitud, las actividades y las prácticas cristalizan en formas expresivas muy concretas y coherentes" (2014: 273). Este proceso de generación estilística lo explicó Clarke haciendo "un uso parcial y un tanto ecléctico" del concepto de bricolage de Levi-Strauss, esto es

...el reordenamiento y recontextualización de objetos para comunicar nuevos significados, en el contexto de un sistema total de significaciones que incluye significados previos y sedimentados de esos objetos utilizados. Juntos, objeto y significado constituyen un signo, $y$, en cualquier cultura, esos signos son ensamblados, de modo recurrente en formas características de discurso. Sin embargo, cuando el bricoleur recoloca al objeto significante en una posición diferente dentro de ese discurso, usando el mismo repertorio general de signos, o cuando el objeto es ubicado en un ensamblaje diferente, se constituye un nuevo discurso, se emite un nuevo mensaje. (2014: 273-274).

La teoría subcultural clásica centra su análisis en el discurso de la moda, explicando ejemplos de bricolage como el del uso del imperdible dentro de la escena punk: un desplazamiento de un objeto del mundo de la costura que pasa a convertirse en complemento estético, resignificándose y convirtiéndose en un símbolo de ostracismo y negación social. De este modo, los objetos más triviales cobran una "dimensión simbólica y acaban convirtiéndose en una especie de estigmas, en las pruebas del exilio autoinfligido" y juegan un doble papel ya que por un lado, "las tensiones entre grupos dominantes y grupos subordinados pueden verse reflejadas en las superficies de las subculturas", $y$, por otro, para aquellos que erigen estos objetos en iconos, se convierten en "signos de una identidad prohibida, fuente de valor" (Hebdige, 2004: 15).

Aquí, sin embargo y teniendo en cuenta que estamos trabajando con un medio de comunicación, nos centraremos en cómo a través del bricolage aplicado al lenguaje, las emisoras libres crearon y pusieron en circulación una serie de representaciones de lo alternativo y de aquellas personas que lo componían. Una realidad sobre la que ya Stuart Hall llamó la atención al señalar que "la mayoría de las subculturas tienden a dramatizar la brecha entre su propio 'mundo' y el mundo de los 'otros' a través del lenguaje” (1970: 15) y que María Teresa Santos Díez identificó en sus trabajos sobre la radio en Bilbao, al reconocer que las emisoras libres siempre emplearon "su propio lenguaje y su jerga distintiva" (1999: 42).

Analizando la documentación que ha llegado hasta nuestros días, hemos podido observar que se emplearon dos formas de crear estilo subcultural jugando con el lenguaje. La primera constituyó un claro ejemplo de bricolage, en el que algunas palabras - significantes - se insertaron en una nueva matriz cultural, resignificándose; 
y la segunda se basó en pequeños juegos con el lenguaje, como deconstrucción e invención de palabras.

De la primera modalidad encontramos ejemplos en documentación escrita producida por las propias emisoras. Es interesante apuntar que, en estos casos, el ejercicio de bricolage se cruzaría, a la hora de generar representaciones e identidad, con aquello que Stuart Hall, en sus trabajos sobre los estereotipos raciales y el racismo, denominó transcoding: "coger un significado preexistente y reapropiárselo para dotarlo de nuevos significados", normalmente en positivo (2009: 270).

Comenzaremos analizando un ejemplo perteneciente a Onda Sur, una de las primeras radios de este tipo en Madrid, que fue puesta en marcha por el Colectivo Ecologista de Villaverde en el distrito del mismo nombre. En 1983, en el periódico Cisneros aparecía un artículo que recogía que la emisora era

la más escuchada por los alpinistas frustrados, los antinucleares, los barbudos, los indios metropolitanos, los garbanzos negros, los soldados que están en las garitas aburridos de oírnos, los antiguos alumnos de colegios de curas y monjas... (Alguacil, 1983: 15).

El autor, miembro de la radio, enumera quiénes constituían la audiencia de este proyecto de comunicación alternativa. Más allá del tono socarrón del listado, que incluye a antiguos alumnos de instituciones religiosas y a soldados - grupos que a priori no pertenecerían a la esfera de lo alternativo-, es interesante ver que recoge, como colectivos interesados en sus emisiones, a "los alpinistas frustrados", tal vez una velada alusión a los ecologistas; a "Ios antinucleares", movimiento social en auge en aquellos años (Camacho Palencia, 2018); a "los barbudos", posible doble referencia a una estética desaliñada heredada del movimiento hippie o a los revolucionarios cubanos; y a los "indios metropolitanos", identidad "tribal" alternativa surgida dentro de la autonomía italiana en el contexto de las movilizaciones de 1977 (Morey, 1977: 65-66). Esta pluralidad de realidades la englobó el autor del texto bajo la categoría de "los garbanzos negros", realizando así el doble ejercicio de bricolage lingüístico y trans-coding. Un significante, "garbanzos negros", que remite a la expresión que, de acuerdo con el Diccionario de la lengua española $(D L E)^{1}$, define a una "persona que se distingue entre las de su clase o grupo por sus malas condiciones morales o de carácter" y que aquí, desplazada de su matriz cultural original, pasará a definir a todas aquellas personas que englobaba la subcultura alternativa.

Al igual que el punk con el imperdible, lo "alternativo" utiliza aquí el lenguaje como elemento de exilio autoimpuesto. La subcultura reconocía que para la cultura dominante todo lo que la rodeaba era motivo de exclusión y que sus planteamientos

\footnotetext{
${ }^{1}$ Tanto esta, como las sucesivas definiciones de palabras que aparecen a lo largo del artículo están obtenidas de la versión on-line de dicho diccionario: https://dle.rae.es/.
} 
altermundistas, su crítica social y su propensión a la movilización constituyeron las "malas condiciones morales" que hicieron que se la distinguiese de su grupo de pertenencia, esto es, la sociedad española. Esta resignificación producida a través del desplazamiento que implica el bricolage subcultural va acompañada de un ejercicio de trans-coding, de ruptura con un estereotipo social a través de su puesta en valor y su reconsideración en positivo. La imagen negativa que proyecta la cultura dominante de este espacio, cercano a la izquierda radical, es reapropiada y resignificada. Los juegos con el lenguaje, ese estilo de habla propio, crearon una representación de este subconjunto social que valoró positivamente el "estigma" que pesa sobre él, ayudando a la construcción de su identidad e incidiendo en la dramatización de la brecha entre el "ellos" y el "nosotros".

Estos ejercicios fueron comunes a prácticamente todas las emisoras, y es posible encontrar rastros de este bricolage en parte de la documentación que ha llegado hasta nuestros días. Radio Cigüeña, emisora de Rivas Vaciamadrid -localidad cercana a Madrid-, puso en circulación, en un momento indeterminado de la década de 1980, un poema para intentar captar la atención de posibles socios para el proyecto. En un momento dado, los versos dicen así:

...que esto es la jaula de grillos

...que aquí la gente es más rara

que una mosca con flequillo

... Hay poetas, objetores, tíos piraos, feministas,

post-after, new-güeis, cinéfilos

del Atleti, pringaos, perros con moquillo...

y se gasta uno una pasta,

...y se añoran los tresillos...

ESTO ES UNA RADIO LIBRE Y AUNQUE CIGÜEÑA DE EMBLEMA

TIENE MUCHOS MÁS PARIENTES EN LAS MOSCAS COJONERAS (Radio Cigüeña, sin fecha).

Este esfuerzo lírico consiste, principalmente, en resignificar expresiones y realidades culturales con significados y cargas negativas, convirtiéndolas en señas de identidad de la emisora y sus miembros, reforzando esa idea de alteridad. Radio Cigüeña se reafirma en su carácter de los "otros" frente a la cultura dominante. Para el DLE una jaula de grillos es un "lugar en que hay gran desorden y confusión y nadie se entiende", y dentro del caos que supuestamente era la emisora, podían encontrarse personalidades "más raras que una mosca con flequillo", sobre todo "tíos piraos": poetas y cinéfilos; "post- 
after" - juego de palabras con la subcultura musical del post-punk de aquellos años-; "new-güeis" - de nuevo un juego con el fenómeno musical de la new wave anglosajona-; "pringaos" - "persona que se deja engañar fácilmente" según el DLE-; perros con moquillo -enfermedad altamente contagiosa que entre otros síntomas presenta feas erupciones cutáneas-; forofos del Atlético de Madrid -equipo de alguna manera asociado a una imagen de resistencia por eterno "segundón", recordamos aquella campaña publicitaria que rezaba aquello de "papá, ¿por qué somos del Atleti?"-; y, finalmente, objetores de conciencia y feministas. La aparición de dos movimientos sociales dentro de esta enumeración de calamidades incide en esa reivindicación de estos colectivos cuya actividad, una vez convertida España en una democracia con sus normativos cauces participativos basados en la representación, generaba contradicciones a las clases dominantes.

La idea de "mosca cojonera", persona molesta de acuerdo con la Real Academia, se sitúa en una nueva matriz de significado en la que es puesta en positivo. De esta forma la otredad a la que relegaba la sociedad española del momento a este espacio alternativo pasa a constituir una seña de identidad.

Dentro de la segunda modalidad, la modificación de palabras para la creación de otras nuevas, el caso más significativo tal vez sea el de La Cadena del Water. Esta emisora libre constituyó un auténtico fenómeno social en el Madrid del momento y creó una amplia comunidad de oyentes a su alrededor. Una comunidad fan que aún hoy puede rastrearse en redes sociales como Facebook.

El ejemplo más paradigmático de modificación de palabras puesto en circulación por La Cadena del Water fue el de denominar a las personas al cargo de sus emisiones "loputores", una clara mezcla entre el sustantivo locutor/locutora, "aquel que tiene por oficio hablar por radio o televisión" y el adjetivo puto/puta, que se utiliza "como calificación denigratoria", que iría en la línea del lenguaje utilizado por la emisora, caracterizado por su tono popular y la profusión de improperios y palabras malsonantes. Una forma de hablar que la diferenciaba claramente de las radios generalistas e incidía en la idea del estigma diferenciador expuesto más arriba.

No obstante, habría que recuperar momentáneamente la noción recogida en el primer epígrafe de que el movimiento de las radios libres era una realidad heterogénea que, pese a inscribirse dentro de ese espacio alternativo, presentó en ocasiones grandes diferencias entre unas emisoras y otras. La Cadena del Water, dentro del movimiento madrileño, fue un proyecto que intentó diferenciarse del resto de sus compañeras, ya que presentó un perfil más epicúreo que político, si atendemos a la clasificación de este fenómeno dada por Aguilera para el caso italiano (1985: 66), y recientemente adaptada para el contexto español (Pérez Martínez, 2012). Es decir, se trataba de un colectivo que, pese a su praxis y contenidos altermundistas y contrahegemónicos, comenzó a emitir para satisfacer las necesidades comunicativas de sus fundadores. 
Y en este diferenciarse del espectro de las emisoras libres, desde y alrededor de La Cadena del Water se realizaron también interesantes ejercicios de bricolage lingüístico. Su comunidad de oyentes fue tan fiel que pronto comenzó a denominarse como "dementes", en un claro desplazamiento del significado original de la palabra y jugando con la similitud fonética con "oyente". Esta "demencia" terminó por constituir una identidad cultural, como atestiguan las "quedadas" que desde la emisora organizaron con ellos.

El último ejemplo de bricolage que queremos traer a colación es la siguiente cuña de la mencionada radio libre:

"Locutor 1: La estación de Radio la Voz de la Experiencia emite en los ciento seis coma ocho para todos los dementes que la quieran escuchar.

(Música).

Locutor 1: Radio la Voz de la Experiencia, la radio forense porque estamos...

Locutores: iEn el foro!

Locutor 1: Radio la Voz de la Experiencia, la radio feminista porque estamos...

Locutores: iEn efe eme!

Locutor 1: Además de la radio feminista, la radio ímproba, porque siempre estamos...

Locutores: iEn pruebas!

$[\ldots]$

Locutora 2: A veces se emite también los sábados...

Locutor 3: y a veces no...

Locutora 2: a veces se emite los domingos...

Locutor 3: y a veces tampoco...

Locutora 2: a veces emitimos a las cuatro de la mañana...

Locutor 3: o a las cinco de la mañana...

Locutora 2: porque es la radio...

Locutores: iAlternativa!

(Música)

Locutor 1: Y así, sin más prepucios...

Locutores: iiComenzamos!!” (La Cadena del Water, sin fecha). 
Podemos ver un juego con el lenguaje, un desplazamiento de significados, dirigido a marcar distancia, tal vez burlarse, de otras emisoras que estuvieran más comprometidas con la "alternatividad" en la que se insertaron estos proyectos. Un tono provocador que se hace manifiesto en la declaración de ser una radio feminista porque emitían en FM, cuando hemos visto que este movimiento estuvo comprometido con la lucha feminista y que alcanza su cota más alta cuando se declara radio "alternativa" porque sus horarios de emisión varían de un día a otro, transformando totalmente el significado de aquello que daba entidad a la subcultura en la que nacieron las radios libres. Hay que reseñar que este desplazamiento del significado de lo "alternativo" fue constante en la historia de esta emisora ya que, como recuerda uno de sus miembros fundadores, se declaraban una radio alternativa porque ponían música "primero en un plato y luego en otro" (Sobórnez, 2008).

\section{Conclusiones}

El objetivo de estas páginas era, como señalábamos en la introducción, atender a las formas en las que las radios libres crearon, gracias a la cultura mediática desarrollada a su alrededor, una identidad, o una serie de rasgos identitarios, para los miembros de la subcultura alternativa dentro de la que aparecieron estas emisoras, y ver cómo representaron y entendieron su papel en la sociedad española del momento.

Podemos concluir, tras el trabajo desplegado con los ejemplos expuestos, que, efectivamente, estas emisoras ayudaron a construir una identidad para aquellas personas que conformaron el mencionado espacio alternativo. A través de la creación de estilo subcultural, aplicado al lenguaje, estas radios contribuyeron a generar una representación de la sociedad española en la que marcaron la diferencia entre la subcultura y aquellos que no formaban parte de la misma, el "nosotros" y el "ellos", poniendo en valor en muchas ocasiones aquello por lo que quedaban excluidos por la cultura dominante.

Profundizamos, así, en el conocimiento que tenemos sobre este tipo de emisoras y, al ver qué papel jugaron en la sociedad madrileña de la década de 1980, podemos poner en cuestión alguno de los grandes relatos que se han construido sobre la capital, la Movida, la modernidad y el desapego de la juventud de la ciudad con la política y el activismo, el famoso "desencanto".

La existencia de un subconjunto social compuesto por jóvenes que compartían una cosmovisión altermundista y que esta fuese puesta en común a través de medios de comunicación creados por ellos mismos, que también sirvieron para generar, afianzar y distribuir sus señas de identidad, pone en entredicho el relato de la modernización 
hedonista de la ciudad durante los años de implantación y afianzamiento de la democracia en España. Más aún si, como hemos visto, la representación de esta esfera alternativa se construyó en clara oposición a la cultura dominante, la del consenso y la Transición modélica, resignificando en positivo la visión hegemónica que sobre ella se tenía.

El sostén y la cobertura dadas a los movimientos sociales, sumadas a otras realidades como la tendencia a poner música ajena a los circuitos de distribución comerciales o el apoyo a expresiones artísticas marginales y escenas underground, fueron expresiones también de esa (contra)cultura mediática de confrontación, contrahegemónica. Dar voz a "las sin voz" implicaba, a todo los niveles, ofrecer un tipo de contenidos y una forma de comunicar que no tenía cabida en los medios generalistas.

Esta vía de trabajo abre, para el futuro, el camino para, por un lado, comprobar si las hipótesis que hemos confirmado para las radios libres madrileñas se cumplirían en sus homólogas del resto del Estado y, por otro, para analizar cómo evolucionó esta (contra)cultura mediática en las décadas subsiguientes. Debemos, a partir de aquí, preguntarnos cómo afectaron a las dinámicas expuestas a lo largo de este artículo los cambios que se vivieron a nivel global en la década de 1990 con la implantación de las políticas neoliberales, el asentamiento de la democracia en España, el descenso en la intensidad de las movilizaciones sociales y las propias dinámicas del movimiento de las radios libres, que abandonará progresivamente los planteamientos contrahegemónicos para caminar hacia un modelo de intervención e inclusión sociocomunitaria (García García, 2017).

\section{Referencias bibliográficas y fuentes documentales}

AGUILERA, M. (1985), Radios libres y radios piratas, Madrid, Forja.

ALGUACIL, J. (25 de mayo de 1983), "Radios libres en Madrid", Cisneros, p. 15.

ALTHUSSER, L. (2014), "Ideología y aparatos ideológicos del Estado (notas para una investigación", en Althusser, L., La filosofía como arma de la revolución, Barcelona, Anthropos, pp. 95-142.

BARRANQUERO, A. y MEDA, M. (2015), "Los medios comunitarios y alternativos en el ciclo de protestas ciudadanas desde el 15M", Athenea Digital, 15(1), pp. 139-170. 
CAMACHO PALENCIA, A. (11 de mayo de 2018), "El movimiento antinuclear en España 1977-1990)", en Ecologistas en Acción. Disponible en internet (20-8-2020): https://www.ecologistasenaccion.org/16239/el-movimiento-antinuclear-enespana-1977-1990/.

CAMPS DURBAN, E. (2019), Fem-nos escoltar! Història de les ràdios ciutadanes de l'espai català de comunicación (1977-2017), Maçanet de la Selva, Gregal.

CLARKE, J. (2014), "Estilo", en Hall, S. y Jefferson, T. (eds.), Rituales de resistencia. Subculturas juveniles en la Gran Bretaña de postguerra, Madrid, Traficantes de Sueños, pp. 271-292.

DEO, F.; DOLÇ, M. y SANCHÍs, V. (1985), Radios Lliures: una práctica alternativa, Barcelona, Terranova.

GARCÍA GARCÍA, J. (2013), "Transformaciones en el Tercer Sector: el caso de las radios comunitarias en España", adComunica. Revista de estrategias, tendencias $e$ innovación en comunicación, no 5, pp. 111-131.

- (2017), "Transformaciones y aprendizajes de las radios comunitarias en España: hacia un modelo de radio inclusiva", Disertaciones. Anuario electrónico de estudios en comunicación social, 10(1), pp. 30-41.

GUERRA, P. (2019), "Rádio Caos:resistência e experimentação cultural nos anos 1980", Análise Social, no 231, pp. 284-309.

HALL, S. (1970), Los hippies: una contra-cultura, Barcelona, Editorial Anagrama.

- (2009), "The spectacle of the other", en Hall, S. (ed.), Representation. Cultural representations and signifying practices, Londres, Sage Publications, pp. 223-290.

HALL, S. y JEFFERSON, T. (eds.) (2014), Rituales de resistencia. Subculturas juveniles en la Gran Bretaña de postguerra, Madrid, Traficantes de Sueños.

HEBDIGE, D. (2004), Subcultura: el significado del estilo, Barcelona, Paidós.

LA CADENA DEL WATER (sin fecha), "Cuñas Radio La Voz de la Experiencia. Cadena del Water. Inicio de emisiones", en Youtube. Disponible en internet (30/07/2016): https://www.youtube.com/watch?v=pBooUuH1Mnl.

LACEY, K. (2009), "Ten years of Radio Studies: the very idea", Radio Journal: International Studies in Broadcast \& Audio Media, 6(1), pp. 21-32.

- (2018), "Up in the air? The matter of Radio Studies", Radio Journal: International Studies in Broadcast \& Audio Media, 16(2), pp. 109-126.

LEFEBVRE, T. (2008), La bataille des radios libres 1977-1981, París, Nouveau Monde Editions. 
LEMA, I.; RODRÍGUEZ GÓMEZ, E. y BARRANQUERO, A. (2016), “Jóvenes y tercer sector de medios en España: formación en comunicación y cambio social", Comunicar, no 48, pp. 91-99.

MARTín CABELLO, A. (2006), La Escuela de Birmingham. El Centre for Contemporary Cultural Studies y el origen de los estudios culturales, Madrid, Servicio de Publicaciones de la URJC.

MARTÍNEZ, M. (1998), "Islas de autogestión en un mar de contradicciones. Cuatro movimientos sociales en el Estado español (1978-1998)", Hartza. Disponible en Internet

(2-8-2020): http://miguelangelmartinez.net/IMG/pdf/1998 movimientos sociales Gijon.pdf

MORADIELLOS, E. (1994), El oficio de historiador, Madrid, Siglo XXI Editores.

MOREY, M. (1977), "Los indios metropolitanos ensayan la revolución”, El Viejo Topo, no 8, pp. 65-66.

PASCUAL, J. (2019), Movimiento de resistencia. Años 80 en Euskal Herria. Radios libres, fanzines y okupaciones, Tafalla, Txalaparta

PÉREZ MARTíNEZ, J. E. (2012), "Libertad en las ondas: la radio libre madrileña (19761989)", en Navajas Zubeldia, C. e Iturriaga Barco, D. (eds.), Coétanea. Actas del III Congreso Internacional de Historia de Nuestro Tiempo, Logroño, Universidad de la Rioja, pp. 333-342.

- (2017), “¿Por qué las radios libres invadieron nuestro dial? Reflexiones sobre el concepto de anomia comunicacional como origen de proyectos de comunicación alternativa (1976-1989)", Estudios sobre el mensaje periodístico, no 23 (1), pp. 519-534.

- (2018), "La radio libre en Madrid (1976-1989): Ios orígenes del movimiento por la libertad de emisión", Commons: revista de comunicación y ciudadanía digital, 7 (1), pp. 112-143.

PERROTTA, M. (2013), "Storia della radio in Itlia in quattro atti", en Bonini, T. (ed.), La radio in Italia. Storia, mercati, formati, pubblici, tecnologie, Roma, Carocci Editore, pp. 29-72.

PRADO, E. (1981), "El movimiento por la libertad de emisión en España”, en Bassets, L. (ed.), De las ondas rojas a las radios libres, Barcelona, Gustavo Gili, pp. 237-255.

- (1983), Las radios libres. Teoría y práctica de un movimiento alternativo, Barcelona, Mitre.

- (1999), "Las otras radios", en Balsebre, A. (coord.), En el aire. 75 años de radio en España, Barcelona, Promotora General de Revistas, pp. 224-231. 
RADIO CIGÜEÑA (sin fecha), “... y de postre?” en Radio Cigüeña. Disponible en internet (04/01/2015): http://www.radiociguena.org/imag/rcfiestaspermanente.jpg

RODERO, E. (2009), "Y siempre, por último, con ustedes: la radio. Revisión de la producción bibliográfica y hemerográfica radiofónica en España", Admira, nำ1, pp. 98-126.

SANTOS DÍEZ, Ma T. (1994), Radios comerciales — ondas libres, Bilbao, Onda Cero.

SANTOS DÍEZ, Ma T. (1999), La radio vasca (1978-1998), Bilbao, Servicio Editorial Universidad del País Vasco.

SOBÓRNEZ, A. (2008), Entrevista personal. Miembro fundador de La Cadena del Water, Madrid.

THEODOSIADOU, S. (2010), "Pirate radio in the 1980s: a case study of Thessaloniki's pirate radio", The Radio Journal - International Studies in Broadcast and Audio Media, 8/1, pp. 37-49.

VAN DER HOEVEN, A. (2014) "The popular music heritage of the Dutch pirates: illegal radio and cultural identity", Media, Culture \& Society, 34/8, pp. 927-943.

WILLIAMS, R. (2009), Marxismo y literatura, Buenos Aires, La Cuarentena. 